\title{
Integrated definition modeling and Taguchi analysis of flexible manufacturing systems: aircraft industry application
}

\author{
Mehmet Pınarbaşı • Çagrı Sel • Hacı Mehmet Alağaș • \\ Mustafa Yüzükırmızı
}

Received: 24 September 2012 / Accepted: 1 February 2013 /Published online: 21 February 2013

(C) The Author(s) 2013. This article is published with open access at Springerlink.com

\begin{abstract}
In this paper, flexible manufacturing systems (FMS) are studied. Firstly, an FMS design approach is proposed using integrated definition for function methodology. A systematic layout design and performance evaluation scheme is presented and detailed using this modeling framework. Then, the proposed approach is carried out with a case study from an aircraft industry to convert an existing traditional production system to FMS. To improve the system performance, a simulation-based method with Taguchi approach consisting of multiproducts is utilized. The objective is to find the machine and the product mix that achieves the maximum utilization while minimizing the cycle time. FMS system performance has been greatly improved by determining the most advantageous level of system components. It has also shown that FMS is a practicable production system in aircraft industry.
\end{abstract}

Keywords Flexible manufacturing systems - Taguchi experimental design $\cdot$ Simulation $\cdot$ IDEF $\cdot$ Aircraft industry

\section{Introduction}

Manufacturing systems confront an increasing pressure to improve productivity and efficiency while swiftly adapting

M. Pınarbașı $(\bowtie)$

Department of Industrial Engineering, Faculty of Engineering, Hitit University, Çorum 19030, Turkey

e-mail: mehmetpinarbasi@hitit.edu.tr

C.. Sel

Department of Industrial Engineering, Faculty of Engineering, Dokuz Eylül University, İzmir 35160, Turkey

H. M. Alağaş • M. Yüzükırmızı

Department of Industrial Engineering, Faculty of Engineering, Kırıkkale University, Kırıkkale 71450, Turkey to changing market conditions. To encounter most of these issues, a new type of production system has emerged: flexible manufacturing systems (FMS). FMS are complex manufacturing systems which consist of four distinct components: computer-aided machines, robots, material handling systems, and a computer network. Due to high investment costs of components, an FMS design process should be thoughtfully carried out and the system must be carefully constructed. Utilizing machines to their extent and obtain the maximum output from these systems are the general objectives. Still, to achieve a well-designed FMS, several parameters should be taken into account and essential performance measures should be examined.

In this context, anticipating bottlenecks caused by machinery and/or processes are very important for FMS in design and operation phase. To accurately determine the behavior of a system and to make inferences from the concept model, performance studies should be done beforehand.

In this study, firstly, a systematic layout design and performance evaluation scheme is proposed using integrated definition for function (IDEF) modeling framework. Secondly, the proposed approach is validated with an application to an aircraft industry using real-life data. Products, manufacturing process, and machine requirements are taken as inputs. Cycle time and machine utilizations are used to form operating characteristic (OC) curves. Subsequently, relations between design parameters are analyzed via Taguchi design of experiments approach. Accordingly, favorable parameter levels are determined by analyzing these relations.

This paper is organized as follows: In Section 2, a comprehensive literature in designing FMS is presented. Section 3 explains the IDEF modeling for a FMS design process. In Section 4, experimental procedures and numerical results are presented. Also, the simulation technique with Taguchi approach is illustrated and configurations of the experiments are 
explained. Section 5 completes the paper with conclusions and future researches.

\section{Literature review}

In this section, we first present the related literature in the design of FMS. The review is divided into main approaches on various aspects of design methodology and performance evaluation with specific attention paid to FMS.

\subsection{Researches using Petri networks}

In earlier studies, Petri networks were commonly used in FMS design as a tool to examine relationships between parameters and also for the modeling of transactions. Stotts et.al. [1] described a logical structure for modeling of FMS using Petri Networks. The authors have discussed the robot lattice structure, one of the most flexible manufacturing line structures, by using a timed Petri nets. In another study, Santarek and Buseif [2] have suggested an automatic logical control model for FMS design with structured analysis design techniques (SADT) and Petri networks. In their paper, they described an approach for manufacturing systems design which allowed automatic generation of controller logic from a high-level system design specification. The high-level system design specification was developed using SADT method and IDEF software package. Yim and Barta [3] presented a simulation model based on Petri networks. In their study, three models - object model, Petri net model, and control model - have been developed. While hardware components of FMS have modeled by Petri net objects, control functions have been separately modeled and integrated with a Petri net model to resolve conflicts occurring in Petri net execution. In a recent article, Turgay [4] has studied agent base FMS control system. The author proposed Petri net for designing FMS and evaluated the performance using time placed Petri nets. The waiting time of the parts in queue and the task distributions were taken as performance criterions. El Tamimi et al. [5] have studied another concept and implementation of the Petri nets for measuring and analysis of FMS performance. The system has been modeled with simulation. A mathematical technique has also been applied for the purpose of comparison and verification of the simulation results. Petri nets have been used to manage FMS system dynamics as deadlock prevention and avoidance. Similarly, Abdallah and ElMaraghy [6] used Petri nets to develop efficient deadlock prevention and deadlock avoidance methods for FMS. Last but not least, Chincholkar and Chetty [7], used stochastic-colored Petri nets and Taguchi method of design of experiments to efficiently and realistically model, simulate and analyze a manufacturing system.

\subsection{Researches using simulations}

Simulation is a modeling tool used in complex systems designs preferably than analytical and mathematical approaches. With the facilitation of advances in technology and software, manufacturing and FMS simulations vastly increased. In the beginning of the millennium, Klingstam and Gullander [8], Ahmari and Ridgway [9], and Anglani et al. [10] have introduced simulation models for FMS designs.

To give a brief detail, Al-Ahmari and Ridgway [9] have presented a modeling method developed to meet the requirements of manufacturing system analysis and design. Their integrated modeling method presented the global view of the manufacturing system in a single level grid and used IDEF0 to model every activity center. Lowest levels of activity center, described by the IDEF0 sub-activity models, then translated into a simulation modeling tool to measure and evaluate system performance.

Meanwhile, Anglani et al. [10] have presented a new procedure to develop FMS simulation models, based on the ARENA simulation software. In their study, two main features were defined: a systematic conceptual procedure to design FMS simulation models and a set of rules for the conceptual model translation in a simulation language.

Recently, Subulan and Cakmakci [11] have also studied relations between performance optimization of automation technologies and the design of material handling-transfer systems. In their research, many experimental investigations revealed that the speed and capacity of automated-guided vehicle, the capacities of local depots, and the mean time between shipping from the main depot were the major influential parameters. In another recent study, Shirazi et al. [12] has proposed working intelligent adaptive controller prototype. They have described an intelligent cosimulator for realtime production control of a complex flexible manufacturing system. The system has been implemented by coupling of the centralized simulation controller and real-time simulator for enforcing dynamic strategies of shop floor control.

Related to our study in the way of using simulation with Taguchi methods, the studies of Bhagwat and Wadhwa [13] and Banerjee and Bhattacharya [14] are worth mentioning. Bhagwat and Wadhwa [13] investigated the contribution of various factors, including the decision delays using Taguchi methods, in a manufacturing system. Their results indicated that the relative contribution of decision delay on makespan performance is the maximum. Also, Banerjee and Bhattacharya [14] have employed Taguchi approach with simulation in the performance evaluation of automated-guided vehicles (AGVs).

\subsection{Researches using object-oriented architecture}

Another approach used in FMS design is object-oriented architecture. This technique does not depend on any 
programming language and uses objective models of system parameters [15]. Kovacs et al. [16] have developed object oriented models on reusing FMS components. The purpose of their research was to obtain methods and tools to build FMS simulation models and control strategies easily, fast, and reliably.

In another study, Choi et al. [17] have presented a method for constructing a graphical model of an FMS by using a new modeling tool called Job Resource relation-net (JR-net). It was an object-oriented graphical tool for modeling automated manufacturing systems. Step-by-step procedure for constructing a graphical model of FMSs has been given by using the extended JR-net.

\subsection{Other related researches}

FMS and FMS components design using various methodologies are studied extensively. Arbel and Seidmann [18] have improved the FMS implementation performance with costbenefit analyses. Bi and Zhang [19] have stressed on a study consisting of various background and solution methods. Benito Martin and Paredes [20] have developed a method called Flexible Autonomous Management System Architecture using multi-agent systems. Recently, Chan et al. [21] have introduced a study using Taguchi to analyze physical and operational parameters that affect FMS performance. The results of their study have showed that the expected benefits from increasing the level of flexibility may not be achieved if the physical and operating parameters of alternative machines have variations. And another study of Chan et al. [22, 23] focused on FMS operating under review period-based control and presented a combined study of routing flexibility, control strategies, and information system under Taguchi's method using simulation. Chen and Chen [24] have studied using multi-agent technique for multisection FMS model can enhance the production efficiency. They have used multi-agent technology to construct a multisection FMS model. They utilized simulation to build a manufacturing environment based on Java Agent Development Framework for multi-agent to combine with dispatching rules; such as shortest imminent processing time, first come first serve, earliest due date and buffer sequence. They aimed to identify the best dispatching rule combination for achieving largest throughput. In another study, Borenstein [25] developed a multicriteria decision model for evaluating FMS with competing design alternatives.

The Shin et al. [26] proposed a decision support model for the design and evaluation of FMS. The model was solved by using the closed queuing network model and optimization model iteratively. Park et al. [27] presents a method for simultaneously determining design and control parameters of an FMS with the multiple performance objectives via full-factorial design of experiments, regression analysis and compromise programming with simulation. The purpose of Baykasoğlu and Özbakır [28] was to investigate the effects of process plan and machine flexibilities on the scheduling performance of manufacturing job shops using Taguchi method. Caprihan and Wadhwa [29] presented a framework based on a Taguchi experimental design for studying the nature of the impact of varying levels of routing flexibility on the performance of an FMS.

There are some literature reviews or state of art about FMS design, performance evaluation, and analysis of flexibility. Gatelmand [30] used the different flexible manufacturing for machining and assembling in the following countries are reviewed. Buzacott and Yao [31] researched the analytical models for FMS in their survey. To design the FMS with Petri nets, review of Moore and Gupta [32] can be examined. Flexibility analysis of FMS is surveyed in the study of Sethi and Sethi [33] and Beach et al. [34]. And to consider the simulation study for FMS, you can see Chan et al. [35].

Table 1 summarizes some existing techniques done in the last decade. Different researches in designing flexible manufacturing systems have been introduced. As previously noted, the use of IDEF is very limited in the FMS design literature. To the best of our knowledge, there exists no implementation of simulation based TED with IDEF technique to the FMS design process. Hence, these foundations will lead the future researchers and practitioners in using Taguchi and IDEF methodology to design the FMS.

This research differs from existing literature, in the way of;

1. Using Taguchi experimental design

2. Dealing with the FMS design using IDEF in details

3. Carrying out the simulation experiments with Taguchi and IDEF simultaneously,

4. Considering all FMS components simultaneously.

\section{Flexible manufacturing system design}

FMS design is a very difficult and complex process for manufacturing companies. It is also a crucial decision with respect to the present and future strategies of the companies. These decisions involve determination of appropriate design parameters such as number of machines, transporters and other devices. In this respect, a design model relevant to FMS is required and this research intends to fulfill this need.

\subsection{System design process}

A comprehensively and clearly modeled system reduces complexity, design cost and time. In this context, IDEF0 framework for FMS designs is proposed. IDEF is one of the 
Table 1 Characteristics of some existing techniques for FMS design

\begin{tabular}{|c|c|c|c|c|c|c|}
\hline Paper & $\begin{array}{l}\text { Petri } \\
\text { network }\end{array}$ & Simulation & $\begin{array}{l}\text { Object-oriented } \\
\text { architecture }\end{array}$ & $\begin{array}{l}\text { Multi- } \\
\text { agent }\end{array}$ & IDEF & Taguchi \\
\hline Stotts et al. [1] & $\checkmark$ & & & & & \\
\hline Klinstam and Gullander [7] & & $\checkmark$ & & & & \\
\hline Yim and Barta [3] & $\checkmark$ & $\checkmark$ & & & & \\
\hline Al-Ahmari and Ridgway [8] & & $\checkmark$ & & & $\checkmark$ & \\
\hline Choi et al. [14] & & & $\checkmark$ & & & \\
\hline Anglani and et al. [9] & & $\checkmark$ & $\checkmark$ & & & \\
\hline El-Tamimi et al. [5] & $\checkmark$ & $\checkmark$ & & & & \\
\hline Santarek and Buseif [2] & $\checkmark$ & $\checkmark$ & & & $\checkmark$ & \\
\hline Turgay [4] & $\checkmark$ & & $\checkmark$ & $\checkmark$ & & \\
\hline Chincholkar and Chetty [7] & $\checkmark$ & $\checkmark$ & & & & $\checkmark$ \\
\hline Subulan and Cakmakci [10] & & $\checkmark$ & & & & $\checkmark$ \\
\hline Shirazi et al. [11] & & $\checkmark$ & & & & \\
\hline Bhagwat and Wadhwa [13] & & $\checkmark$ & & & & $\checkmark$ \\
\hline Banerjee and Bhattacharya [14] & & $\checkmark$ & & & & $\checkmark$ \\
\hline Kovacs et al. [13] & & $\checkmark$ & $\checkmark$ & & & \\
\hline Benito Martín and Paredes [17] & & & $\checkmark$ & $\checkmark$ & & \\
\hline Chan et al. [18-22] & & $\checkmark$ & & & & $\checkmark$ \\
\hline Chen and Chen [19] & & $\checkmark$ & & $\checkmark$ & & \\
\hline Terkaj eet al. [23] & & & & & $\checkmark$ & \\
\hline Matta et al. [25] & & & & & $\checkmark$ & \\
\hline Matta et al. [26] & & & & & $\checkmark$ & \\
\hline
\end{tabular}

SADT developed by Douglas T. Ross. Firstly, IDEF was applied in The US Air Force Integrated Computer-Aided Manufacturing [36, 37].

IDEF function framework consists of inputs, controls, outputs, and mechanisms which are abbreviated as ICOM. Figure 1 shows IDEF methodology [36]. Function or activity is related to the response of "what to do" question. Inputs are necessary objects and data to form the function. These are service times, machine and tool information, product, and process info for a production system design process. Outputs are objects or data generated as a result of function. Controls are parameters required to fulfill the function. Mechanisms can be a person, data, or device which

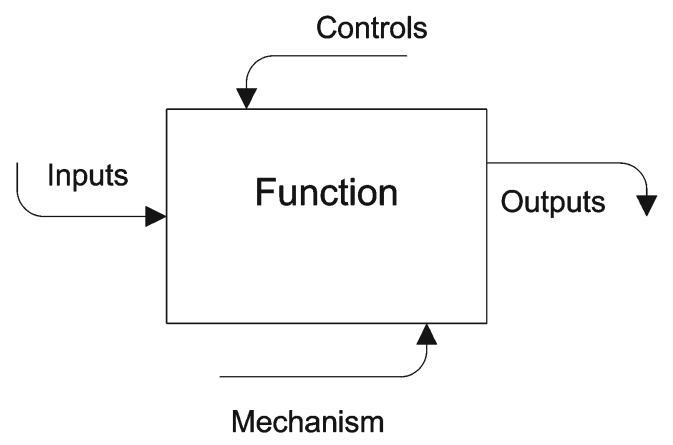

Fig. 1 IDEF diagram components performs the function. In a FMS design process, inputs can be products, production processes, related costs and devices, etc. The control elements are budget, design constraints, and strategic decisions. The mechanisms are various economical, analytical, heuristic tools, job enlargement techniques, and such. The resultant outputs may be feasible and unfeasible designs and design costs. Figure 2 illustrates inputs, outputs, controls, and mechanism using IDEF0 diagram for a FMS design [38-40].

In detail, A0 FMS design process and subfunctions can be explained as follows:

- A1 function (system requirements) contains necessary data which is collected and compiled in system set-up.

- Data compiled in the previous function is input to A2 process design function which is determined by production processes.

- A3 layout design and performance evaluation function is the alternative FMS cell layout and evaluation of the alternatives with data obtained from A1 and A2 functions. Thus far, a FMS is designed with obtained data and inferences.

- A4 system performance analysis function measures the designed system with considered criteria. We may take precautions and send them as feedback to considered function. 
Fig. 2 IDEF0 diagram of FMS system design

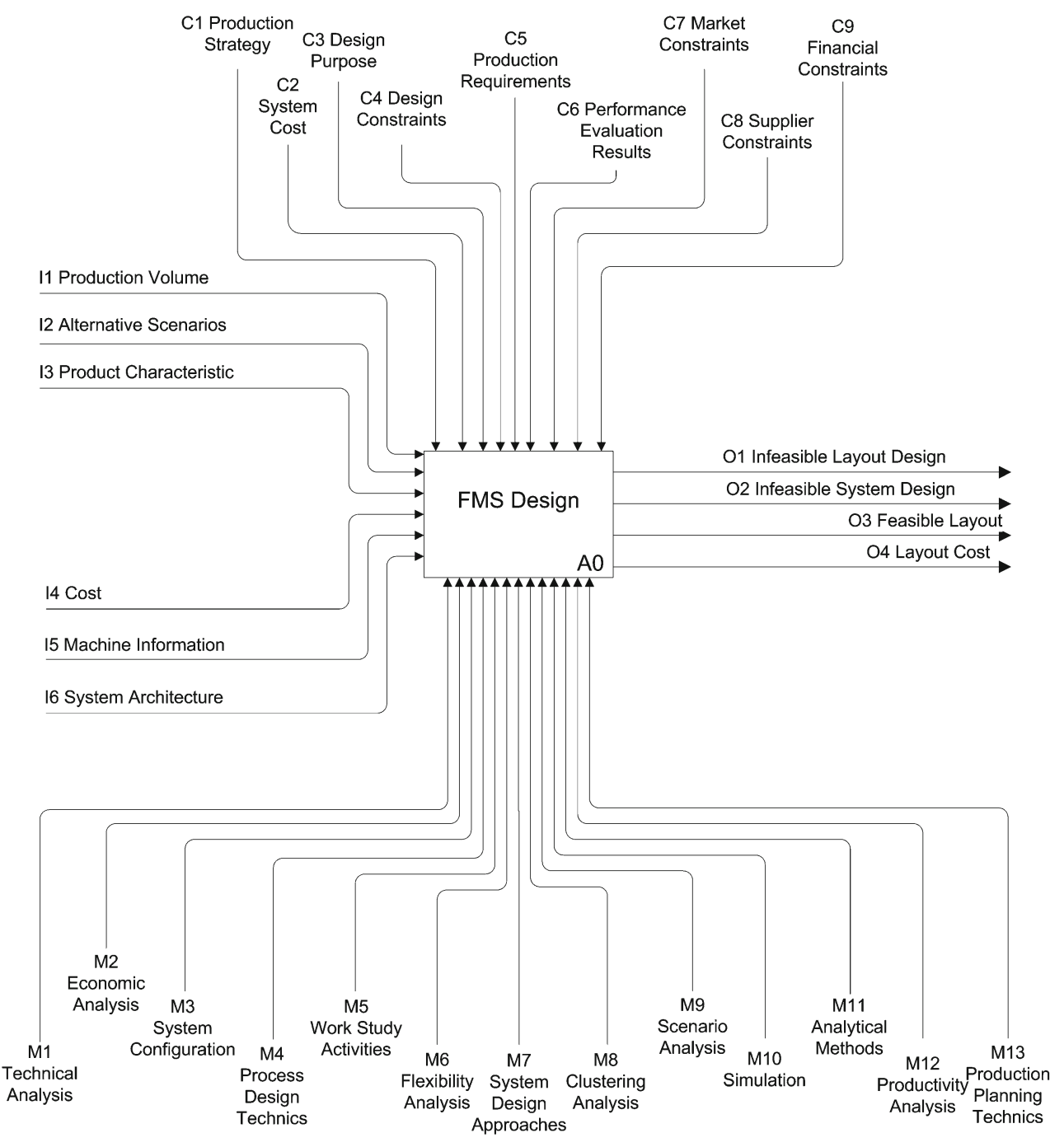

- When performance analyses are on acceptable level, A5 application process function is conducted.

The focus of this study is the FMS system design and performance evaluation for aircraft industry [41]. Hence, A3 layout design and performance evaluation (Fig. 3) subfunction is presented. For presentation purposes, the details of A1, A2, A4, and A5 functions are omitted. These details were study of an extensive research and can be found in [41] and [42]. IDEF diagram components which are related to A3 function are explained below (Table 2).

A31-Generate alternatives This function defines the alternative layouts of the system designs considering all the possible plans. The following outputs are obtained in consideration of the inputs, controls and mechanisms which are presented in Table 2.

- Technical data, consisting of the information of workspace, energy requirement, number of machines, machine technical brief, time, and transportation info so as to evaluate the system performance.

- FMS alternatives related to possible and appropriate FMS layouts to meet the system demand.

A32-Evaluate alternatives This function is performed to determine optimum FMS design among all alternative layouts which are obtained in A31 function. At the end of the function, we obtain the performance measures; throughput, jobs, machine utilization, and the cycle time. Hence, performance evaluation function should be determined accurately and exactly. The results of A32 function provide feedback to A31 and input to A33 function.

A32 function produces the performance data. In general, it is related to minimizing transport, storage and retrieval time while maximizing machine utilization. This function's output data is also used in determining alternative performance parameters. 
Fig. 3 IDEF context diagram layout design and performance evaluation

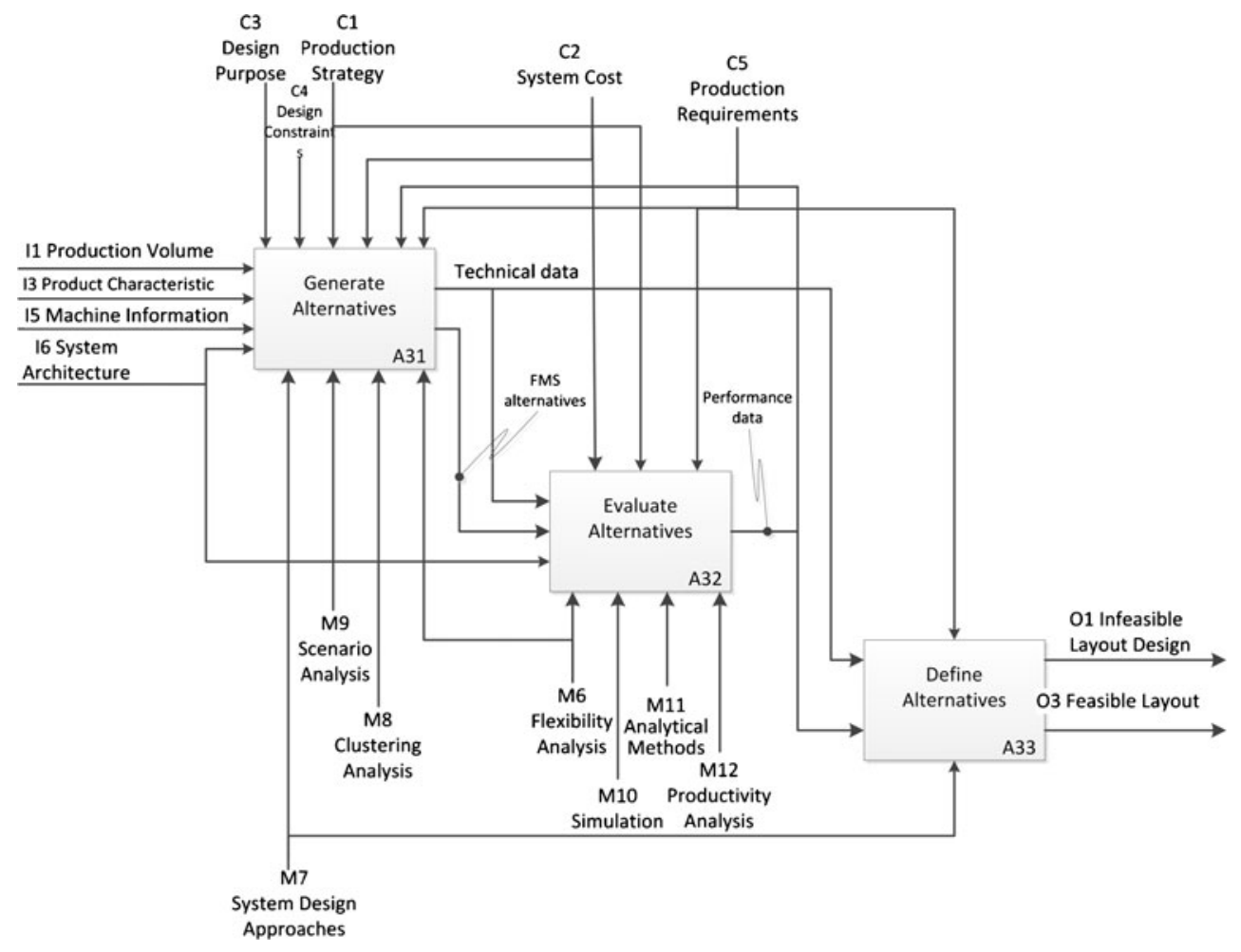

A33-Define alternatives The evaluated alternatives are inspected in this function whether it is feasible for application. The function obtains the outputs: O1, infeasible layout design, and $\mathrm{O} 3$, feasible layout, yields the data of system components, cost, and production rate.

\section{A field application: the FMS modeling of an aircraft company}

The design model which is described above has been performed with an Aircraft Company in Turkey. The company, which ranks among the top hundred global players in aerospace and defense arena, based its business on production of air vehicle components. The company currently uses traditional manufacturing systems and considers if a FMS is a better alternative.

\subsection{Analysis of the existing system}

Firstly, Aircraft Company's existing job shop layout has been analyzed and a simulation study is carried out for verification of the model. Then, inputs and performance parameters have been determined using IDEF of system design process. Using these performance parameters, a new FMS design for the company is proposed.

Existing system flow starts with loading and unloading station and continues with eight other stations according to job sequences which are given in Table 3 for four main product types. These products comprise the majority and their process times are given in Table 4. In the simulation model, transportation between stations is operated by AGV.

We propose a new FMS cell considering A3 layout design and performance evaluation function (Fig. 4). The simulation model of the FMS is also developed in Arena 11.0 software and tested against to the existing system. For validation, the effect of varying number of input parameters as transporters, buffers, alternative machines, pallet, and production type are analyzed. The performance measures of completion time and machine utilization are compared. The simulation is replicated ten times and the model is run totally $110,000 \mathrm{~min}$ where warm-up time is $10,000 \mathrm{~min}$. Subsequently, verified simulation model is evaluated and improved using design of experiments via Taguchi approach.

\subsection{FMS design of experiments using Taguchi approach}

Taguchi experimental design methodology is considered to achieve the best FMS performance. The production system is improved by defining factors in a systematic manner;

1. Controllable factors, which influence directly the response and their levels can be determined at the will of the experimenter

2. Uncontrollable factors, which are either unidentifiable, difficult to control, or not economically controllable which have also influence on the response 
Table 2 Layout design and performance evaluation process ICOM

\begin{tabular}{|c|c|c|}
\hline Component & Name & Definition \\
\hline \multirow[t]{4}{*}{ Inputs } & I1-Production volume & Planned amount of product which is subject to capacity constraints \\
\hline & I3-Product characteristic & $\begin{array}{l}\text { Quantitative and qualitative features which are based on technological specifications } \\
\text { and customer demand }\end{array}$ \\
\hline & I5-Machine information & $\begin{array}{l}\text { Technological, quantitative and qualitative features about machine which is available } \\
\text { for new system design }\end{array}$ \\
\hline & I6-System architecture & Fundamental structure underlying system behavior and operating mechanism \\
\hline \multirow[t]{5}{*}{ Controls } & $\mathrm{C} 1$-Production strategy & $\begin{array}{l}\text { Strategic decisions and preferences which are to be taken to organize the } \\
\text { production by producer }\end{array}$ \\
\hline & C2-System cost & Components cost for setup the system \\
\hline & C3-Design purpose & $\begin{array}{l}\text { We have some goals (e.g., reducing the carrying, optimize the system times etc.) } \\
\text { to design the system }\end{array}$ \\
\hline & C4-design constraints & $\begin{array}{l}\text { Restrictions like acreage, machine and product, building structure constraints } \\
\text { etc. while designing the system }\end{array}$ \\
\hline & C5-Production requirements & $\begin{array}{l}\text { Technological information like unsold product, stock level, raw materials and } \\
\text { semi-finished product for to fulfill the customer demand }\end{array}$ \\
\hline \multirow[t]{7}{*}{ Mechanisms } & M6-Flexibility analysis & $\begin{array}{l}\text { Analyses which are to optimize the flexibility of production process, product, } \\
\text { work flow, enlargement, operation and production management }\end{array}$ \\
\hline & M7-System design approaches & Techniques are used to design the system processes with flexible (e.g., robust design) \\
\hline & M8-Clustering analysis & Clustering techniques are related to organize the system components \\
\hline & M9-Scenario analysis & To determine the alternatives system design \\
\hline & M10-Simulation & To measure the alternatives system design performance before setup the system \\
\hline & M11-Analytical methods & To measure the system performance with analytical techniques \\
\hline & M12-Productivity analysis & To determine the system efficiency with quantitative or parametric analyses techniques \\
\hline \multirow[t]{2}{*}{ Outputs } & O1-Infeasible layout design & $\begin{array}{l}\text { In consequence of performance measurement, a design which does not reach } \\
\text { the allowable performance value }\end{array}$ \\
\hline & $\mathrm{O} 2$-Feasible layout & $\begin{array}{l}\text { In consequence of performance measurement, a design which reaches the } \\
\text { allowable performance value }\end{array}$ \\
\hline
\end{tabular}

Figure 5 shows the factors affecting the FMS design in detail.

Controllable factors can be the number of transporters, buffers, alternative machines, pallets, and the product types. To find an answer how they affect the response variable, quantity of these factors should be chosen appropriately. If these factors are not determined suitably, the overall system performance can be negatively affected. We analyzed the effect of the product types, the number of transporters, and the alternative machines among all factors, since these factors have a crucial importance in a FMS design (see Fig. 3).

Table 3 Work flows

\begin{tabular}{ll}
\hline Product code & Work flow \\
\hline $70207-06051-119 \mathrm{~T}$ & $239-100-551-100-864-100-402-100-22$ \\
$70207-06051-110$ & $239-137-109-151-100-551-100-551-$ \\
& $151-402-100-864-100-22$ \\
$70203-06050-102$ & $239-137-100-864-100-22$ \\
$70201-06157-117$ & $239-137-109-114-100-551-864-100-22$ \\
\hline
\end{tabular}

Uncontrollable factors are determined as manufacturing capacity, transport type, tool life, tool changing time, number of edge, bills of material, product families, and others (see Fig. 5).

The effects of all possible factors on response variable needs to be evaluated. Relations between these factors should also be investigated. Taguchi experiments are

Table 4 Machines and operations

\begin{tabular}{lll}
\hline $\begin{array}{l}\text { Machine } \\
\text { number }\end{array}$ & Operation & $\begin{array}{l}\text { Process } \\
\text { time (min) }\end{array}$ \\
\hline 109 & Surface cleaning & 4 \\
137 & Row material cutting & 2 \\
151 & Deep press & 6 \\
100 & Operator process & 15 \\
864 & Quality control & 30 \\
114 & Hydro press & 6 \\
551 & Heat treatment & 35 \\
402 & Aluminum aging and steel heat treatment & 15 \\
22 & Out & \\
\hline
\end{tabular}


Fig. 4 Visual model of proposed FMS layout

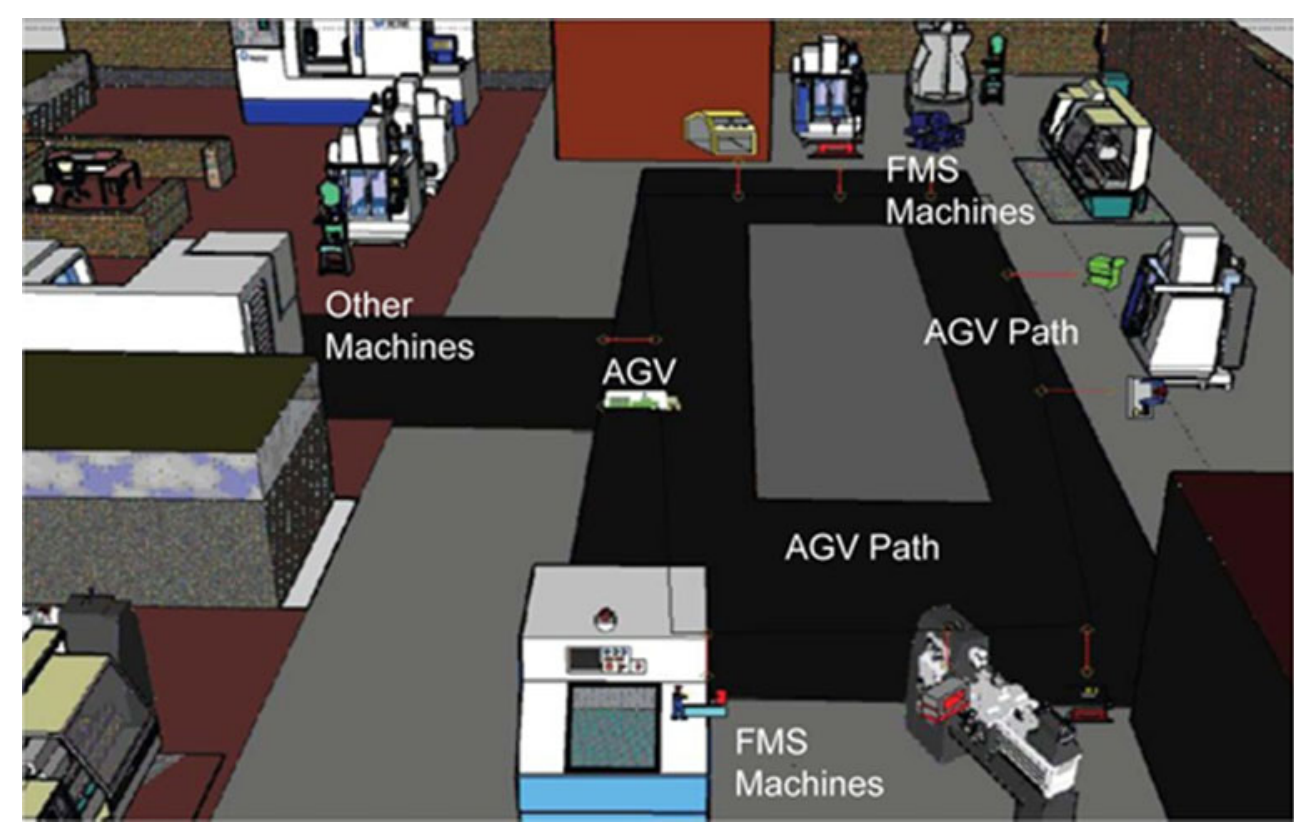

conducted to fulfill the necessary assessments by taking account of relations between these factors. Taguchi technique is a powerful design of experiments tool, which provides a simple, efficient and systematic approach to determine optimal process parameters. Compared to the conventional approach of experimentation, this method reduces drastically the number of experiments that are required to model the response functions.
Taguchi method uses signal-noise $(\mathrm{S} / \mathrm{N})$ ratio as the quality characteristics of choice. These characteristics can be divided into three categories:

- Smaller is the best characteristic

- Larger is the best characteristic

- Nominal (minimum variation from the target) is the best characteristic
Fig. 5 Factors diagram

\section{Controllable Factors}

Number of transporters, buffers, number of alternative machines, number of pallets, number of production type

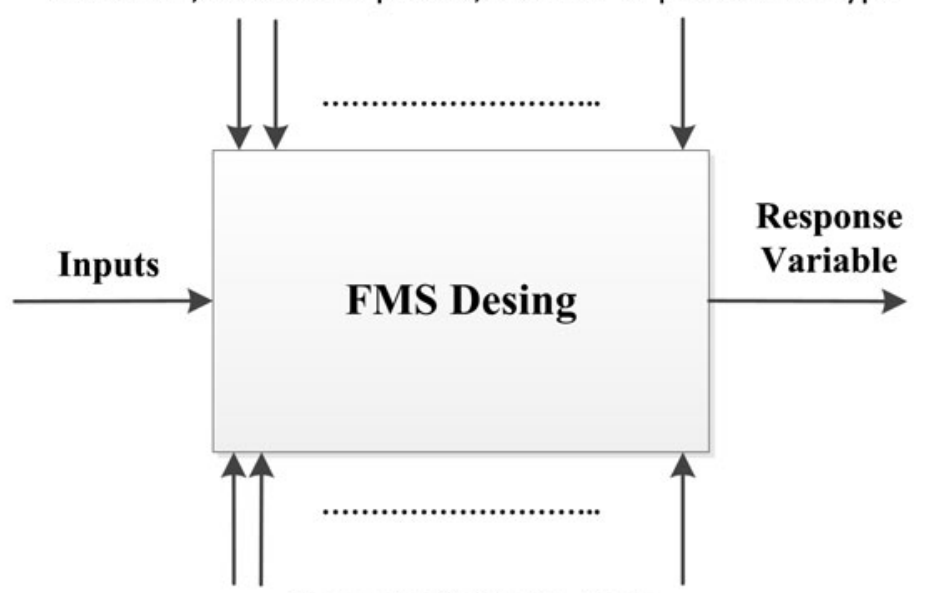

Uncontrollable Factors

Manufacturing capacity, transporter type, tool life, tool changing time, bills of material, product families, cutting speed, dispatching rules, feeder capacity, deep of cut, machine setting time, waiting time, loadingunloading time, processing time, number of operator, sequencing rules, pallet types 
For an FMS design, the machine capacities should be used at their extent. It can be observed that if the workload increases for a production process, the utilizations of workstations also get higher, as well as the waiting time and the cycle time of the system. But, at the physical system capacity, the cycle time increases exponentially compared to utilization. In this context, the response is designed to deal with both the average machine utilization and the cycle time. We know that there is an adverse interaction between these two response variable. Therefore, Eq. 1 is introduced as a quantitative proportion, which is a type of larger-thebetter response variable. This objective function is multiobjective and tries to maximize the utilization while minimizing the cycle time, simultaneously. It is used as the response variable in Taguchi approach.

$Y=\frac{\left[\frac{\sum_{i=1}^{m} u_{i}}{m}\right]}{\left[\frac{\sum_{i=1}^{n} w_{i}}{n}\right]}$

$u_{i} \quad$ Utilization of station $i$

$w_{i} \quad$ Cycle time of station $i$

$m$ Number of machine

$n \quad$ Number of product

The experiments are conducted with no repetition as L32 fractional factorial experiment and simulations are executed for each experiment. We are aware that the mean is not only enough to get efficiency well and the variation analysis is required. Therefore, the pilot experiments are applied in two stages to get efficient results. We also deal with 32 combinations (8,192 combinations/256 fractions) with $r=1$ reputation and $n=13$ factors in a fractional factorial experiment. Observations are practiced in two and more alias to examine all 32 combinations in L32 fractional experiment. To design and analyze the experiments Minitab 11 software package is used.

\subsection{Experimental procedure and numerical results}

In this section, experimental procedure has been carried out in four subsections. Firstly, initial parameter levels and their response values obtained from the simulation are presented. Secondly, the experiment results of the first Taguchi design are given and certain significant parameters and their interactions are discussed. Counter and surface plots of these interactions are presented to explain the results clearly. Third, the experiment results of the second Taguchi design are conferred. Finally, the existing situation in the company and the confirmation results of the new FMS design are compared statistically. Because of multiparameters analysis in Taguchi experiments, we performed further related analysis results instead of introducing the whole parameters results. And also OC curves which are marked up by utilization and cycle time are compared.

\subsubsection{Initial parameter levels and their response values}

Parameter levels are assumed from standards of the factory. Initial parameter level for number of transporters is taken as 1. Then primary levels of the machines are assumed as 1 because of the requirement to understand bottlenecks. There are four product families with 10 pallets each in the existing

Table 5 Parameter levels

\begin{tabular}{|c|c|c|c|c|c|}
\hline Parameter groups & Parameters & $\begin{array}{l}\text { Existing } \\
\text { situation }\end{array}$ & $\begin{array}{l}\text { First } \\
\text { experiments }\end{array}$ & $\begin{array}{l}\text { Second } \\
\text { experiments }\end{array}$ & $\begin{array}{l}\text { Confirmation } \\
\text { experiments }\end{array}$ \\
\hline Number of transporters & N.o.t & 1 & $1-4$ & $3-4$ & 4 \\
\hline \multirow[t]{8}{*}{ Number of alterative machines } & 100 Operator process & 1 & $2-4$ & $2-4$ & 3 \\
\hline & 109 Surface cleaning & 1 & $2-4$ & $2-4$ & 3 \\
\hline & $402 \mathrm{Al}$ aging and steel heat treatment & 1 & $2-4$ & $2-4$ & 3 \\
\hline & 151 deep press & 1 & $2-4$ & $2-4$ & 3 \\
\hline & 137 row material cutting & 1 & $2-4$ & $2-4$ & 3 \\
\hline & 114 Hydro press & 1 & $2-4$ & $2-4$ & 3 \\
\hline & 551 Heat treatment & 1 & $2-4$ & $2-4$ & 3 \\
\hline & 864 Quality control & 1 & $2-4$ & $2-4$ & 4 \\
\hline \multirow[t]{4}{*}{ Production type } & 70203-06050-102 & 10 & $0-20$ & $0-20$ & 10 \\
\hline & $70207-06051-110$ & 10 & $0-20$ & $0-20$ & 10 \\
\hline & 70201-06157-117 & 10 & $0-20$ & $0-20$ & 10 \\
\hline & 7057-06051-119 T & 10 & $0-20$ & $0-5$ & 5 \\
\hline \multirow[t]{2}{*}{ Response values } & $\mu$ & 0.018483 & 0.031658 & 0.042381 & 0.089855 \\
\hline & $\sigma$ & & 0.031605 & 0.032933 & \\
\hline
\end{tabular}


Fig. 6 Normal plot of $Y$ for first experiments

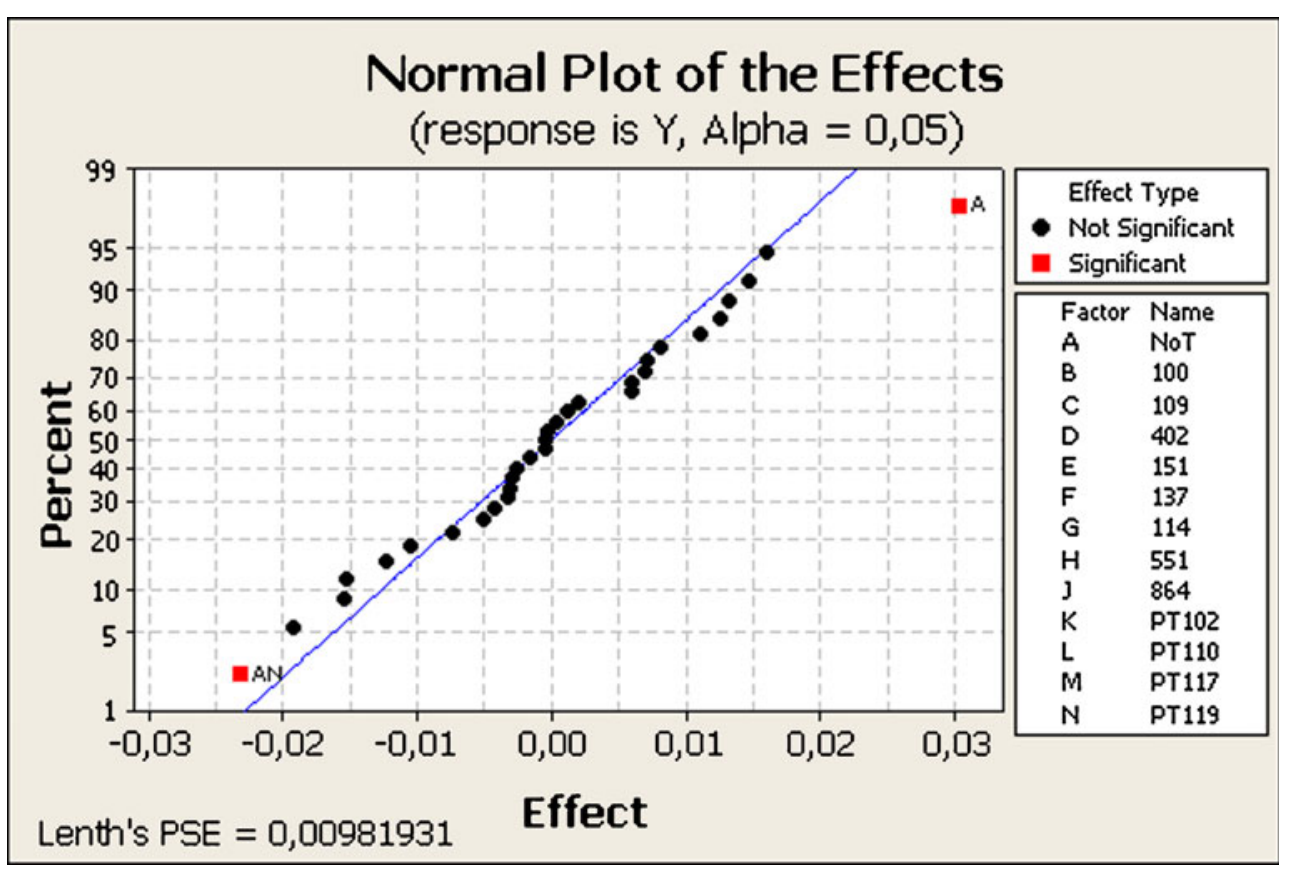

system. These parameters are chosen to identify the characteristic of the fundamental FMS design. They are also used in the first Taguchi experiments. Table 5 shows the parameter levels in each Taguchi phase. The parameter groups which are referred previously as controllable factors are given in rows, while columns are the Taguchi experiments in sequence. In the last row, response variable is shown with mean value $(\mu)$ and standard deviation $(\sigma)$.

\subsubsection{First Taguchi experiments}

Taguchi experiments are operated in two steps. In the first step, parameter levels are investigated to understand the effects and their interactions on a middle sized interspace. Normal plot of the effects is a chart which shows the effect between response and parameters is given in Fig. 6. As it can be derived from the plot, the parameter $A$ and the interaction $A-N$ have important effects on $Y$ response means. $A$ indicates number of transporter and $A-N$ shows relationship or interaction between number of transporter and 119 product type. Normal plot of effects on $Y$ response variable also emphasizes that these parameters should be examined in detail.

When the effect of number of transporter on $Y$ response value is evaluated, Fig. 7 leads us to assign higher levels. It is, however, not convenient to assess this plot without the interaction between number of transporter and 119 product type (PT119). $A-N$ interaction plot shows that there is a negative relationship.

This interaction is evaluated in detail by using contour and surface plots in Fig. 8. These plots lead us to choose the higher level of the number of transporters while a lower level of the 119 product type. The main purpose of the experiment is to improve the $Y$ response variable. Maximum $Y$ value is, therefore, obtained on the corner of the plot.
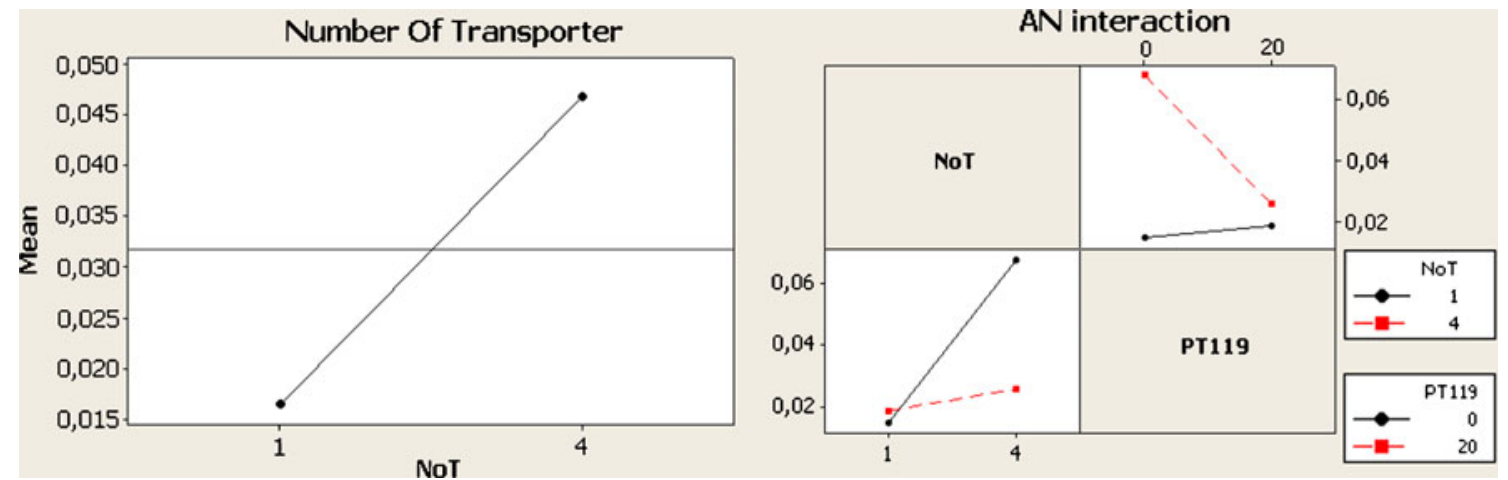

Fig. 7 Main effects of not and interactions between Not-PT119 

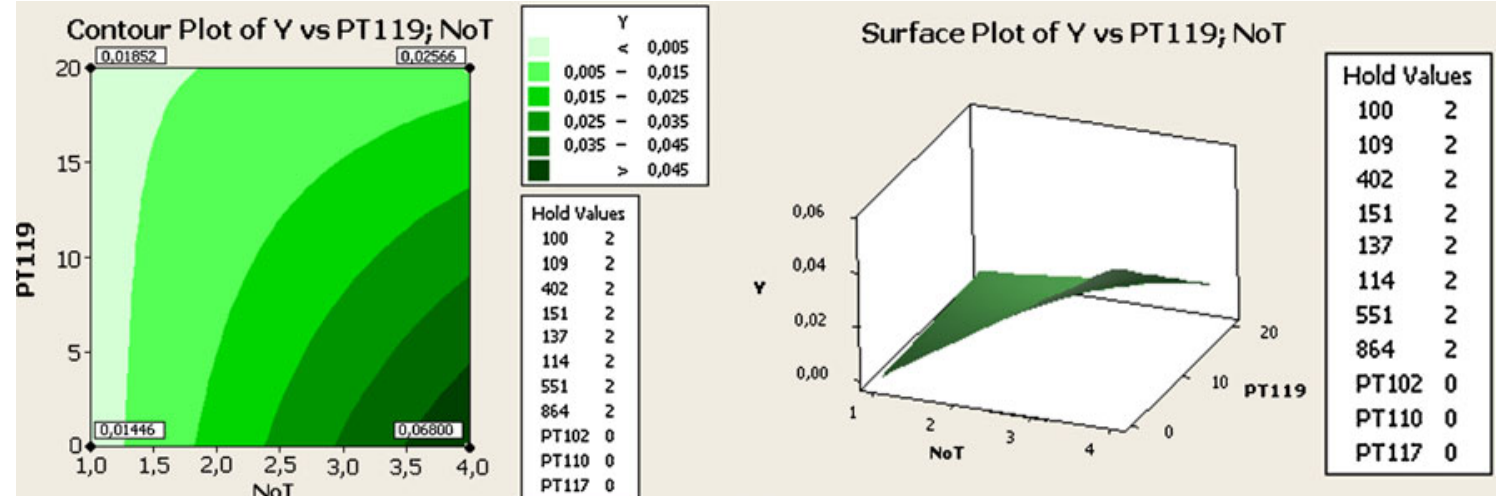

Fig. 8 Contour and surface plots of $Y$ vs Not-PT119

Groundwork gathered from first experiments show the way in the following steps. The level of number of transporter is increased to 3-4 and the level of product type 119 is decreased to $0-5$. Subsequently, other components' relations on the response variable $Y$ are analyzed in Fig. 9. All relationships verify the result of the first experiments which has just one meaningful interaction between the number of transporter and the product type of 119 .

\subsubsection{Second Taguchi experiments}

The second experiments are conducted by using levels shown in Table 5 in accordance with the first Taguchi experiments. There is no more important interaction between parameters and also between the number of transporter and the product type of 119. As in Section 4.3.2, firstly the experiments are analyzed via normal plot of standardized effects
(Fig. 9). Because of the significance of $J$ variable, there exists just one main effect on $Y$ response. The variable $J$ indicates the number of alternative machines for quality control (864). This result also requires an analysis in detail.

The effects of the alternative machine number on $Y$ response variable are analyzed in Fig. 10. Since the objective of our response is the maximum, the quantity of quality control machine (864) is increased to 4 in accordance with Fig. 10.

As a result of this analysis, a linear effect is observed on $Y$ response. It leads us to assign the upper level of this parameter. Afterwards, no reasonable interaction is observed. Therefore, number of transporter is determined as 4 to decrease bottlenecks, while the number of alternative machines are as 3 , just 864 quality control machine is increased to 4 in regulation with the second Taguchi experiments. Accordingly, the three of all product types are
Fig. 9 Normal plot of Y2 for second experiments

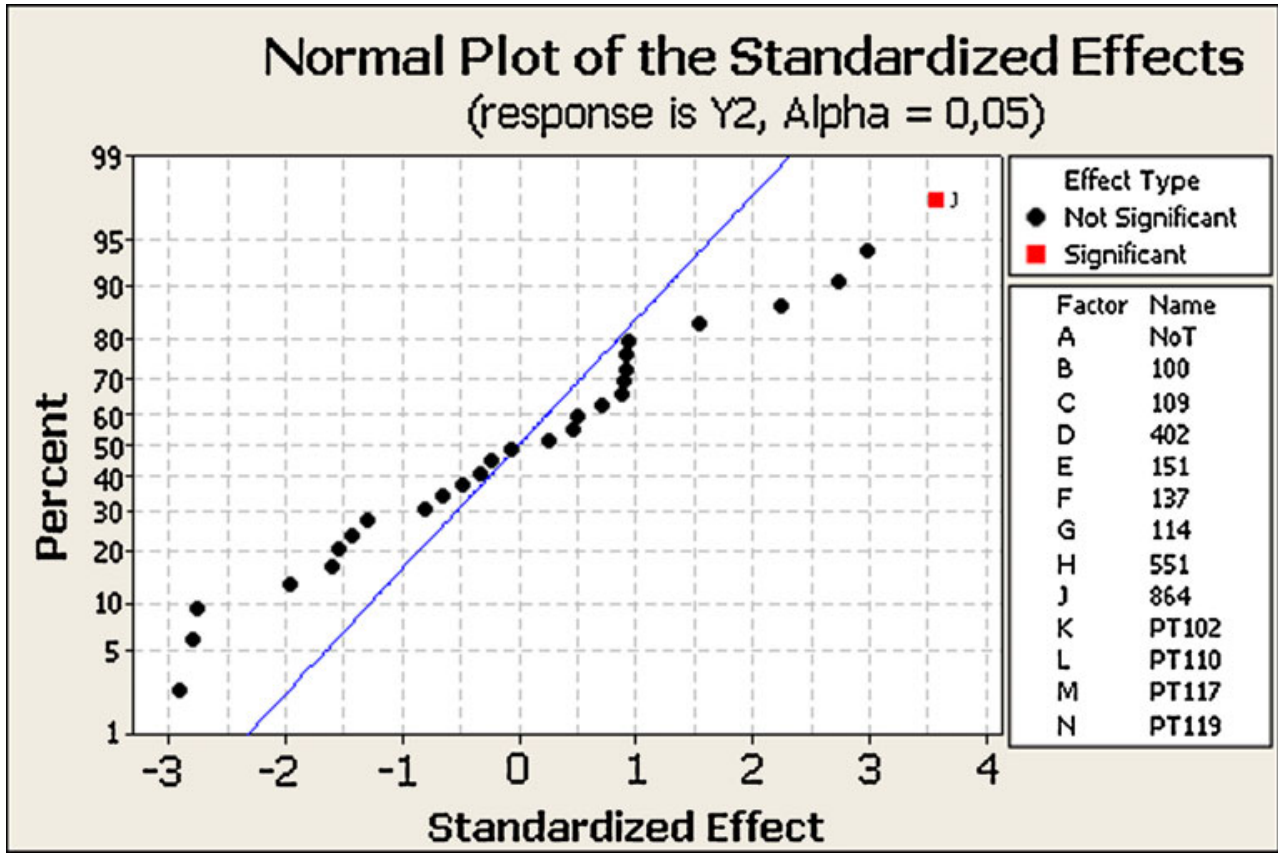


Fig. 10 Main effects plot of Y2 for second experiments

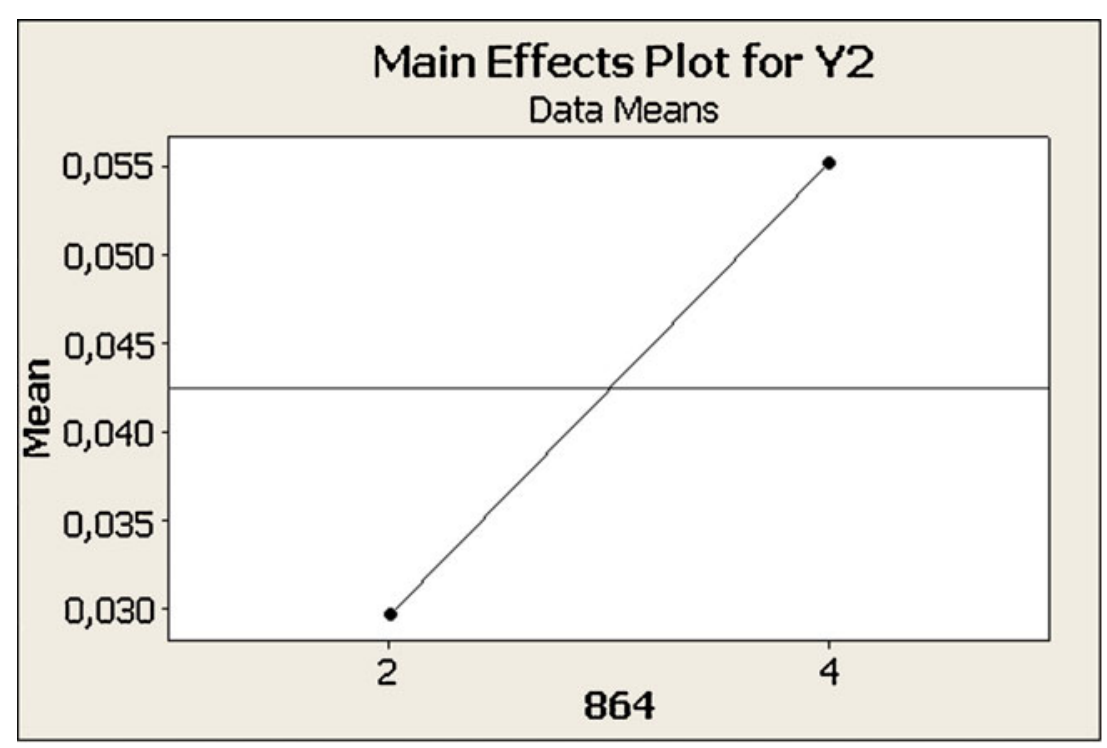

designated as 10, while just 119 product type is chosen as 5 . The results are summarized in Table 5.

The response quality of the eventual system is increased as a result of Taguchi experiments. While standard deviation of the second experiments is close to each other, response value of the second experiments is observed as higher than the first experiments. Therefore, not only the second design of the FMS is better than the first, but also the existing and confirmation experiments.

\subsubsection{Confirmation experiment}

OC curves are graphics which show relations between two or more parameters [43]. The existing parameter levels and the confirmation experiment $\mathrm{OC}$ curves are studied to compare the utilization and the cycle time. OC also helps us to understand the effects of our experiments on the response variable.
The result of the confirmation experiments shows that the utilization is increased while the cycle time is decreased. OC in Figs. 11 and 12 represents the trade-off between cycle time and utilizations.

The cycle time is decreased by an average of $76 \%$ for all product types (Fig. 11). The greatest relatively difference between the cycle times among all products is for $119 \mathrm{~T}$ with approximately $85 \%$. Also, the lowest difference is for product type 110 with $65 \%$. Figure 12 shows that utilizations are relatively higher on the confirmation experiments than the existing experiments. The average relatively differences between the existing and the confirming Taguchi experiment is approximately $13 \%$, the minimum difference is for machine $151 \mathrm{DP}$ with $6 \%$ and the maximum difference is for machine $137 \mathrm{RMC}$ with $51 \%$.

As it can be seen from Fig. 13, a better OC curve obtained for the FMS. This figure indicates that higher
Fig. 11 Utilizationand cycle time comparison

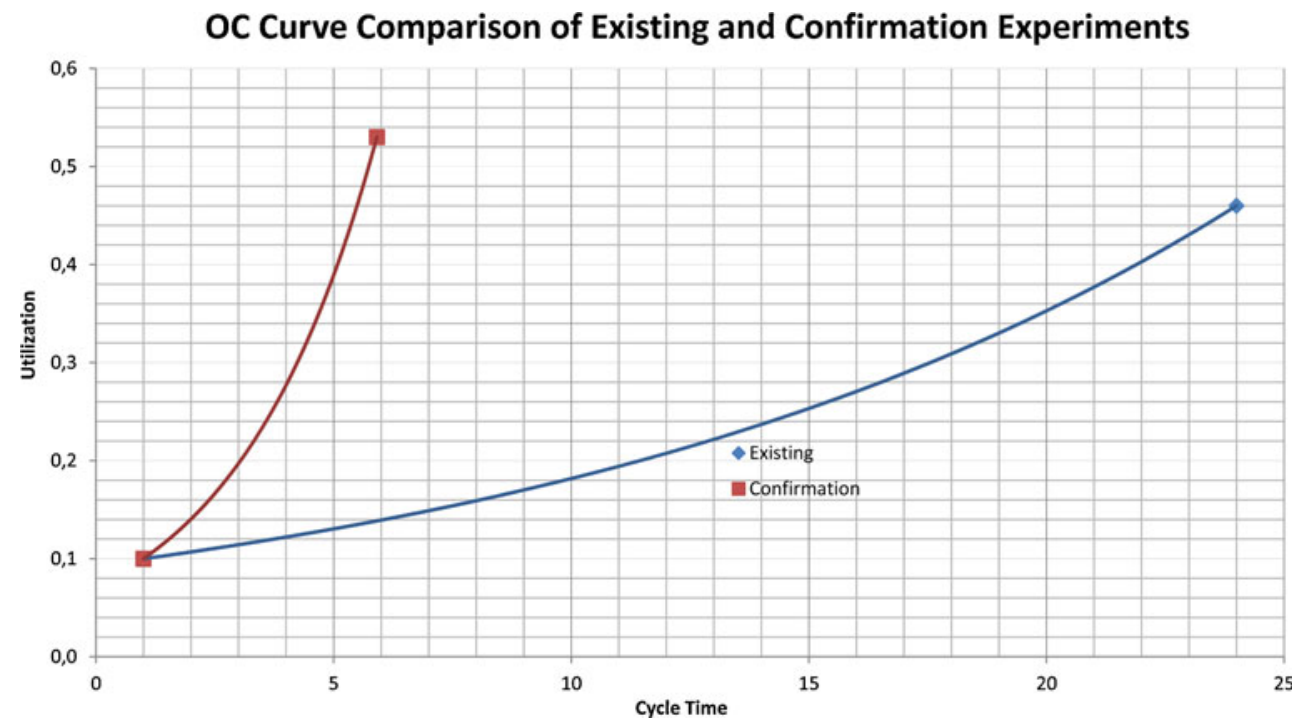


Fig. 12 Evaluation of utilization

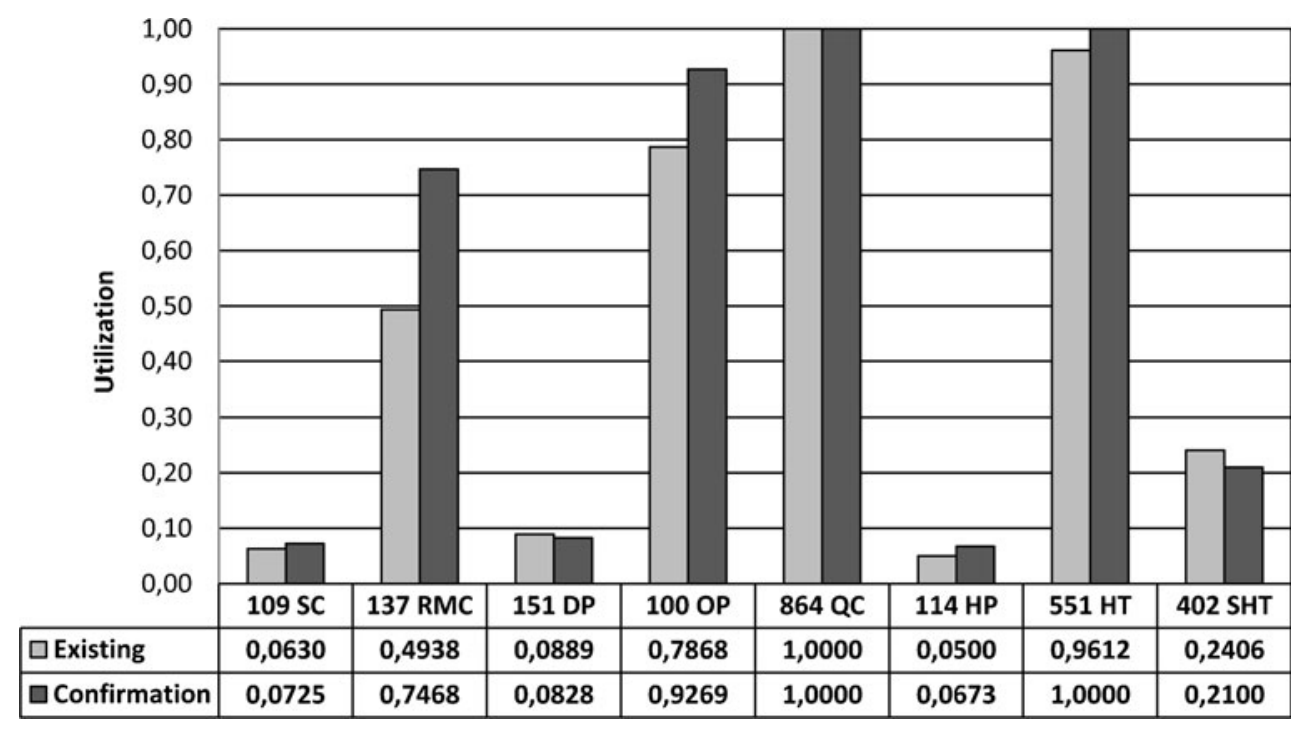

utilization rates are achieved with lower cycle times. The proposed method achieved substantial improvements compared to the performance of existing design. Figure 13 shows the improvements in terms of product cycle times. When we compare to confirmation and existing experiments results, the cycle times are improved the rate of $75 \%$ on the average considering the system performance. And also in Table 5, response variable are enhanced extremely with considerable development as from 0.018483 to 0.089855 . As a result of the experiments, a better FMS process is designed to modernize the existing system using Taguchi methods and an integrated modeling technique called IDEF.

Fig. 13 Evaluation of cycle

time

\section{Conclusions}

FMS design process is a very difficult and complex process which involves determination of appropriate design parameters with inside and outside constraints. In this respect, a design model relevant to FMS is required and this research addresses this necessity.

In this study, firstly, a comprehensive integrated model using IDEF to design FMS is presented. A systematic Layout Design and Performance Evaluation scheme is presented using IDEF modeling framework. Comprehensive inputs, outputs, controls, and mechanisms to carry out a FMS design process are recommended.

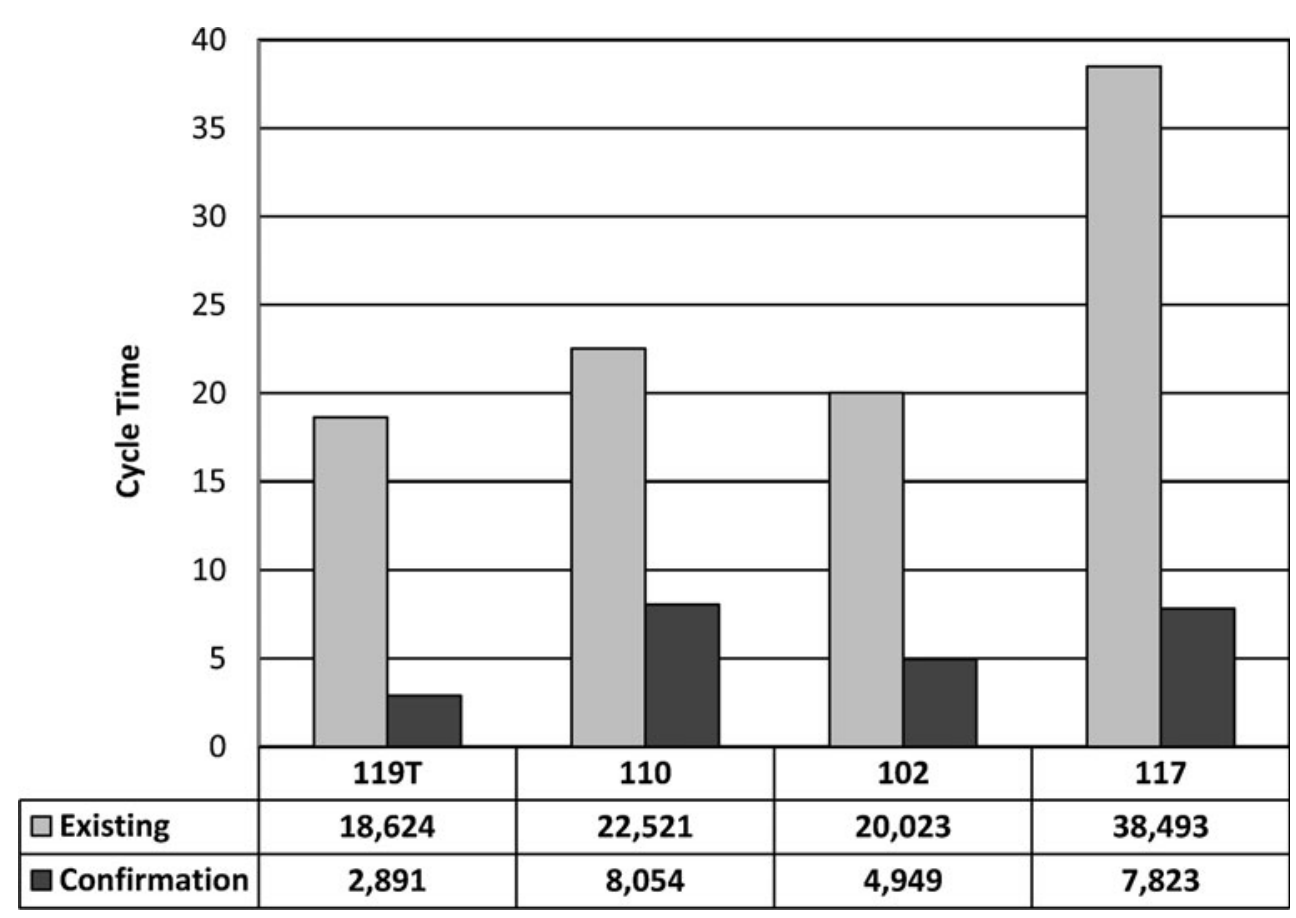


Secondly, the proposed approach is validated with an application to an aircraft industry using real-life data. A simulation-based method with Taguchi approach for FMS consisting of multiproducts is proposed to improve the system performance. Products, manufacturing processes, and machine requirements are taken as inputs. Cycle time and machine utilizations are used to form OC curves. Relations between design parameters are analyzed and favorable parameter levels are determined. As a result, not only the system performance compared to existing system has been significantly improved, but also the FMS quality is enhanced.

The proposed model and the application procedure can be used in other industries besides aircraft industry which employ or plan to employ a FMS. However, much research also remains to be done. Combining other design techniques (Petri nets, object-oriented architecture, etc.) with simulation or other performance measurement techniques along with Taguchi approach and IDEF framework can be conducted. The approaches presented here can also be applied in performance measurement of several production systems such as computer-integrated manufacturing and just in time with appropriate conditions.

Open Access This article is distributed under the terms of the Creative Commons Attribution License which permits any use, distribution, and reproduction in any medium, provided the original author(s) and the source are credited.

\section{References}

1. Stotts DP, Newcomb RW, Cai NZ (1989) Modeling the logical structure of flexible manufacturing systems with Petri nets. Comput Commun 12(4):193-203. doi:10.1016/0140-3664(89)90196-5

2. Santarek K, Buseif IM (1998) Modeling and design of flexible manufacturing systems using SADT and Petri nets tools. J Mater Process Technol 76(1-3):212-218. doi:10.1016/S09240136(97)00350-6

3. Yim DS, Barta TA (1994) A Petri net-based simulation tool for the design and analysis of flexible manufacturing systems. J Manuf Syst 13(4):251-261. doi:10.1016/0278-6125(94)90033-7

4. Turgay S (2009) Agent-based FMS control. Robot Comput Integr Manuf 25(2):470-480. doi:10.1016/j.rcim.2008.02.011

5. El-Tamimi AM, Abidi MH, Mian SH, Aalam J (2011) Analysis of performance measures of flexible manufacturing system. J King Saud Univ Eng Sci 9:9-19

6. Abdallah IB, ElMaraghy HA (1998) Deadlock prevention and avoidance in FMS: a Petri net-based approach. Int J Adv Manuf Technol 14(10):704-715. doi:10.1007/BF01438223

7. Chincholkar AK, Chetty OVK (1996) Simultaneous optimization of control factors in automated storage and retrieval systems and FMS using stochastic coloured Petri nets and the Taguchi method. Int J Adv Manuf Technol 12:137-144. doi:10.1007/BF01178954

8. Klingstam P, Gullander P (1999) Overview of simulation tools for computer-aided production engineering. Comput Ind 38(2):173186. doi:10.1016/S0166-3615(98)00117-1

9. Al-Ahmari AMA, Ridgway K (1999) An integrated modeling method to support manufacturing systems analysis and design. Comput Ind 38(3):225-238. doi:10.1016/S0166-3615(98)00094-3
10. Anglani A, Grieco A, Pacella M, Tolio T (2002) Object-oriented modeling and simulation of flexible manufacturing systems: a rulebased procedure. Simul Model Pract Theory 10(3-4):209-234. doi:10.1016/S1569-190X(02)00100-4

11. Subulan K, Cakmakci M (2011) A feasibility study using simulation-based optimization and Taguchi experimental design method for material handling-transfer system in the automobile industry. Int J Adv Manuf Technol 59(5-8):433-443. doi:10.1007/ s00170-011-3514-0

12. Shirazi B, Mahdavi I, Mahdavi-Amiri N (2011) iCoSim-FMS: an intelligent co-simulator for the adaptive control of complex flexible manufacturing systems. Simul Model Pract Theory 19(7):1668-1688. doi:10.1016/j.simpat.2011.04.003

13. Bhagwat R, Wadhwa S (1998) Simulation study of decision delays in manufacturing systems using Taguchi methods. In Proceedings of IEEE International Conference on Systems Man and Cybernetics, San Diego, CA. pp 2562-2567

14. Banerjee D, Bhattacharya R (2005) Robust design of an FMS and performance evaluation of AGVS. In Proceedings of International Conference on Mechanical Engineering, Dhaka, Bangladesh, pp 1-6

15. Rumbaugh J, Blaha M, Premerlani W, Losenson W (1991) Objectoriented modelling and design. Prentice Hall, Englewood Cliffs

16. Kovacs GL, KopacsiS NJ, Haidegger G, Groumpos P (1999) Application of software reuse and object-oriented methodologies for the modeling and control of manufacturing systems. Comput Ind 39(3):177-189. doi:10.1016/S0166-3615(98)00134-1

17. Choi BK, Han KH, Park TY (1996) Object-oriented graphical modeling of FMSs. Int J Flex Manuf Syst 8(2):159-182. doi:10.1007/BF00394502

18. Arbel A, Seidmann A (1984) Performance evaluation of flexible manufacturing systems. IEEE Trans Syst Man Cybern SMC 14(4):606-617

19. Bi ZM, Zhang WJ (2001) Flexible fixture design and automation: review, issues and future directions. Int J Prod Res 39(13):28672894. doi:10.1080/00207540110054579

20. Benito Martin JJ, Paredes AL (1999) Modelling flexible manufacturing systems as multiagent systems. In Proceedings of International Conference on Modelling and Simulation, Valladolid, Spain, pp 141150

21. Chan FTS, Bhagwat R, Wadhwa S (2007) Flexibility performance: Taguchi's method study of physical system and operating control parameters of FMS. Robot Comput Integr Manuf 23(1):25-37. doi:10.1016/j.rcim.2005.09.002

22. Chan FTS, Bhagwat R, Wadhwa S (2007) Taguchi's method analysis of an FMS under review-period-based operational controls: identification of control periodicity. IEEE Trans Syst Man Cybern 37(2):212-225. doi:10.1109/TSMCA.2006.886355

23. Chan FTS, Bhagwat R, Wadhwa S (2008) Comparative performance analysis of a flexible manufacturing system (FMS): a reviewperiod-based control. Int J Prod Res 46(1):1-24. doi:10.1080/ 00207540500521188

24. Chen KY, Chen CJ (2010) Applying multi-agent technique in multi-section flexible manufacturing system. Expert Syst Appl 37(11):7310-7318. doi:10.1016/j.eswa.2010.04.024

25. Borenstein D (1998) A visual interactive multi criteria decision analysis model for FMS design. Int J Adv Manuf Technol 14:848857. doi:10.1007/BF01350769

26. Shin H, Park J, Lee C, Park J (1997) A decision support model for the initial design of FMS. Comput Ind Eng 33(3-4):549-552. doi:10.1016/S0360-8352(97)00190-3

27. Park T, Lee H, Lee H (2001) FMS design model with multiple objectives using compromise programming. Int J Prod Res 39(15):3513-3528. doi:10.1080/00207540110062381

28. Baykasoğlu A, Özbakır L (2008) Analysing the effect of flexibility on manufacturing systems performance. J Manuf Technol Manag 19(2):172-193. doi:10.1108/17410380810847909 
29. Caprihan R, Wadhwa S (1997) Impact of routing flexibility on the performance of an FMS - a simulation study. Int J Flex Manuf Syst 9:273-298. doi:10.1023/A:1007917429815

30. Gatelmand CD (1982) A survey of flexible manufacturing systems. J Manuf Syst 1(1):1-16. doi:10.1016/S0278-6125(82)80063-0

31. Buzacott JA, Yao DD (1986) Flexible manufacturing systems: a review of analytical models. Manag Sci 32(7):890-905. doi:10.1287/ mnsc.32.7.890

32. Moore KE, Gupta SM (1996) Petri net models of flexible and automated manufacturing systems: a survey. Int J Prod Res 34(11):3001-3035. doi:10.1080/00207549608905075

33. Sethi AK, Sethi SP (1990) Flexibility in manufacturing: a survey. Int J Flex Manuf Syst 2:289-328. doi:10.1007/BF00186471

34. Beach R, Muhlemann AP, Price DHR, Paterson A, Sharp JA (2000) A review of manufacturing flexibility. Eur J Oper Res 122:41-57. doi:10.1016/S0377-2217(99)00062-4

35. Chan FTS, Chan HK, Lau HCW (2002) The state of the art in simulation study on FMS scheduling: a comprehensive survey. Int J Adv Manuf Technol 19:830-849. doi:10.1007/s001700200095

36. Noran OS (2000) Business Modelling: UML vs. IDEF. Lecture note, Griffith University, School of Computing and Information Technology, pp 16-23
37. Shah S (2000) IDEF Modeling. Lecture notes, IMfgE at Wichita State University, pp 1-7

38. Terkaj W, Tolio T, Valente A (2009) Designing manufacturing flexibility in dynamic production contexts. In: Tolio $\mathrm{T}$ (ed) Design of flexible production systems. Springer, Berlin, pp 1-18

39. Matta A, SemeraroQ TT (2005) A framework for long term capacity decisions in AMSS. In: Matta A, Semeraro Q (eds) Design of advanced manufacturing system. Springer, Dordrecht, pp 1-35

40. Matta A, Semeraro Q, Tolio T (2005) Configuration of AMSS. In: Matta A, Semeraro Q, Tolio T (eds) Design of advanced manufacturing system. Springer, Dordrecht, pp 125-189

41. Pınarbaşı, M (2010) Design process of flexible manufacturing systems and performance evaluation with queuing network models. Dissertation, Kirıkkale University Graduate School of Natural and Applied Sciences, Kırıkkale

42. Pınarbașı M, Yüzükırmızı M (2011) Design process model for flexible manufacturing systems and application of TAI. J Fac Eng Archit Gazi Univ 26(4):937-949

43. Olhager J, Persson F (2008) Using simulation-generated operating characteristics curves for manufacturing improvement. Lean Bus Syst Beyond IFIP Int Fed Inf Process 257:195-204. doi:/10.1007/ 978-0-387-77249-3 20 